\title{
Neuroprotective effect of transpupillary thermotherapy in the optic nerve crush model of the rat
}

\begin{abstract}
Purpose Transpupillary thermotherapy (TTT) has been shown to induce heat shock protein (Hsp) 72 in optic nerve head tissue. The neuroprotective effect of TTT was investigated in an optic nerve crush rat model.

Methods TTT was performed onto the optic nerve head in the right eye of subject rats. After $24 \mathrm{~h}$, an optic nerve crush injury using an aneurysm clip was performed at $2 \mathrm{~mm}$ from the optic nerve head for $60 \mathrm{~s}$. At 7 and 14 days later, retrograde labelling of retinal ganglion cells (RGCs) with DTMR crystal was carried out and the density of the surviving RGCs was evaluated. Immunohistochemical staining was performed to confirm the expression of Hsp72.

Results At 7 days after optic nerve crush injury, the mean density of surviving RGCs was higher in TTT group $(372.7 \pm 149.8$ per $\mathrm{mm}^{2}$ ) than in optic nerve crush group $\left(252.9 \pm 96.7\right.$ per $\left.\mathrm{mm}^{2}\right)$ with borderline significance. In the retinal areas at $1 \mathrm{~mm}$ from the optic nerve head, a significant increase in surviving RGCs from TTT treated eyes was observed at both 7 and 14 days after optic nerve crush injury. However, no significant differences in surviving RGCs were demonstrated 2 and $3 \mathrm{~mm}$ from the optic nerve head.

Conclusions These results demonstrate that TTT aimed onto the optic nerve head showed a neuroprotective effect.

Eye (2009) 23, 727-733; doi:10.1038/eye.2008.189; published online 20 June 2008
\end{abstract}

Keywords: heat shock protein; optic nerve crush injury; retinal ganglion cell; transpupillary thermotherapy
SJ Kim ${ }^{1}$, YJ Kim ${ }^{1,2}$ and $\mathrm{KH}$ Park $^{1,2}$

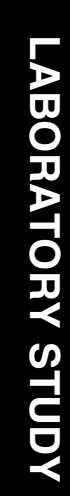

\section{Introduction}

Heat shock proteins (Hsps) are a group of proteins that are upregulated by hyperthermia or other types of physiological and environmental stress. Hsps have been shown to enhance cell survival under conditions of further severe stress. Some of Hsps are constitutively expressed, whereas other Hsps are inducible in response to various kinds of stress. In the nervous system, Hsp70 family, which consists of Hsc70 or constitutive form, and Hsp72 or inducible form, has been shown to have a protective effect against ischaemia, seizures, and axotomy. ${ }^{1-5}$ Also, retinal ganglion cells (RGCs) have been shown to be protected against intraocular pressure elevation or axotomy by induction of Hsp72 by hyperthermia, zinc, as well as medications such as geranylgeranylacetone. ${ }^{6,7}$ RGC death is one of the major pathologic event in glaucoma, so protection of RGCs by induction of Hsps might be a novel treatment strategy to glaucoma. Even though some methods have shown increased Hsps expression with a neuroprotective effect, non-invasive and safe methods to induce Hsps without any systemic effects deserve further investigation.

Transpupillary thermotherapy (TTT) is a treatment modality in which hyperthermic energy is directly delivered to the posterior segment by infrared irradiation. TTT is performed by a diode laser with a broad beam and long exposure times. TTT showed increased temperature in the treated tissue up to $10^{\circ} \mathrm{C}$ above baseline levels. ${ }^{8}$ Using this hyperthermia, TTT has been tried for the treatment of various intraocular tumors (eg, choroidal melanoma, hemangioma, and retinoblastoma) and choroidal neovascularization in age-related macular degeneration. ${ }^{9-13}$ TTT increases the
${ }^{1}$ Department of Ophthalmology, Seoul National University College of Medicine, Seoul, Korea

${ }^{2}$ Seoul Artificial Eye Center, Seoul National University Hospital Clinical Research Institute, Seoul, Korea

Correspondence: KH Park, Department of Ophthalmology, College of Medicine, 28 Yongon-dong

Chongno-gu,

Seoul 110-744 Korea.

Tel: + 8222072 2438; Fax: + 8227413187.

E-mail: kihopark@

snu.ac.kr

Received: 14 January 2008 Accepted in revised form: 26 May 2008 Published online: 20 June 2008 Seoul National University 
temperature in the treated tissue, and therefore TTT may stimulate the expression of Hsps. In a prior report, we showed that TTT performed on the optic nerve head, which is known as a primary site of glaucomatous optic nerve damage, induced expression of Hsp72 effectively in the treated tissue, and found the optimal parameters of TTT for maximal Hsp72 expression without damaging ocular tissues. ${ }^{14}$ The optimal setting for TTT was determined to be $100 \mathrm{~mW}$ for $60 \mathrm{~s} .{ }^{14}$ In this setting, no tissue damage was detected with confocal scanning laser ophthalmoscope, light microscope, and scanning electron microscope as well as fundoscopic examination. As a next step, we applied this to an optic nerve crush injury model of the rat to investigate a possible potential neuroprotective effect.

\section{Materials and methods}

In total, 61 8-week-old male Norway brown rats (Japan SLC, Inc., Hamamatsu, Japan), weighing 200-250 g, were used. The animals were divided into three groups: group A, a normal control group, was used to evaluate the normal RGC density in the retina. Group B was used to investigate the RGC loss after optic nerve crush injury. In group C, the potential effect of TTT on the Hsp expression and survival of RGCs after optic nerve crush injury was investigated. The animals were treated in compliance with the ARVO Statement for the Use of Animals in Ophthalmic and Vision Research and our own institution's guidelines for ethical treatment of animals.

\section{Transpupillary thermotherapy}

Transpupillary thermotherapy was performed in the right eye of 38 group $C$ rats as we previously described. ${ }^{14}$.They were anaesthetized with intramuscular ketamine hydrochloride $(100 \mathrm{mg} / \mathrm{kg})$ and xylazine hydrochloride $(10 \mathrm{mg} / \mathrm{kg})$. Topical $0.5 \%$ tropicamide and $10 \%$ phenylephrine were instilled for mydriasis. TTT was delivered using an adaptor mounted on the slit lamp biomicroscopy with a cover glass as a contact lens on the rat cornea. The cover glass was placed with methylcellulose (Methocel, Novartis Ophthalmics AG, Hettlingen, Switzerland) on the cornea. The $810 \mathrm{~nm}$ diode laser (IRIDEX Corp., Mountain View, CA, USA) was aimed at the centre of the optic nerve head. The TTT setting was as follows: spot size $500 \mu \mathrm{m}$, power $100 \mathrm{~mW}$, and exposure time $60 \mathrm{~s}$, which were the optimal parameters of TTT for maximal Hsp72 expression without damaging ocular tissues. ${ }^{14}$ After TTT, examination of the fundus with indirect ophthalmoscope was performed to detect any change in the retina or optic nerve head. A sham TTT was performed in the right eye of 31 group B rats on the same day. The sham TTT was performed by projection of the aimed beam onto the centre of the optic nerve head without irradiating laser.

\section{Optic nerve crush injury}

At $24 \mathrm{~h}$ after the TTT in group $\mathrm{C}$ and the sham TTT in group B, when maximal expression of Hsp72 by TTT was observed, ${ }^{14}$ an optic nerve crush injury was performed. With the use of a surgical microscope, the right optic nerve was exposed after a superior temporal incision of the limbal conjunctiva and blunt dissection of Tenon's tissue. The optic nerve was then clipped using an aneurysm clip (blade length $5 \mathrm{~mm}$, maximal opening $4.0 \mathrm{~mm}$, force $110 \mathrm{~g}$; MINI Aneurysm-Clips, Aesculap AG, Germany) at $2 \mathrm{~mm}$ from the optic nerve head for $60 \mathrm{~s}$. This optic nerve crush method was slightly modified from the methods by Sarikcioglu et al. ${ }^{15}$ After removing the clip, examination of the fundus with indirect ophthalmoscope was performed to confirm blood perfusion.

\section{Evaluation of RGC Density}

At 7 and 14 days after the optic nerve crush injury, retrograde labelling was performed with the animals in group B ( 8 and 9 rats at 7 and 14 days, respectively) and group C (10 rats each at 7 and 14 days). In 10 rats of group A, retrograde labelling was also performed to count normal RGC density. They were anaesthetized with intramuscular injection of ketamine hydrochloride $(100 \mathrm{mg} / \mathrm{kg})$ and xylazine hydrochloride $(10 \mathrm{mg} / \mathrm{kg})$.

After exposing the optic nerve of the right eye, the sheath of the nerve was cut open longitudinally and a complete cross section of the optic nerve was made. DTMR crystals were applied to the proximal cut surface of the optic nerve to label the RGCs by fast axonal diffusion. ${ }^{6,7,16,17}$ At $24 \mathrm{~h}$ after labelling, all right eyes were enucleated and immersed in $4 \%$ paraformaldehyde for $2 \mathrm{~h}$. Then, the retinas were dissected, flattened with four radial cuts, fixed for an additional $30 \mathrm{~min}$, and mounted with the vitreal side up on glass slides. The retinas were examined with a fluorescence microscope (BX-61, Olympus, Tokyo, Japan). Fluorescence micrographs were taken at 12 standard areas, which included 1,2, and $3 \mathrm{~mm}$ areas from the optic nerve head at each temporal, superior, nasal, and inferior quadrant (Figure 1). Labelled RGCs were counted from fluorescence micrographs. The counting of RGCs was conducted by two investigators in a blinded fashion and the results were averaged.

\section{Immunohistochemical staining}

Induction and localization of Hsp72 were examined by immunohistochemical (IHC) staining. In group C, IHC 


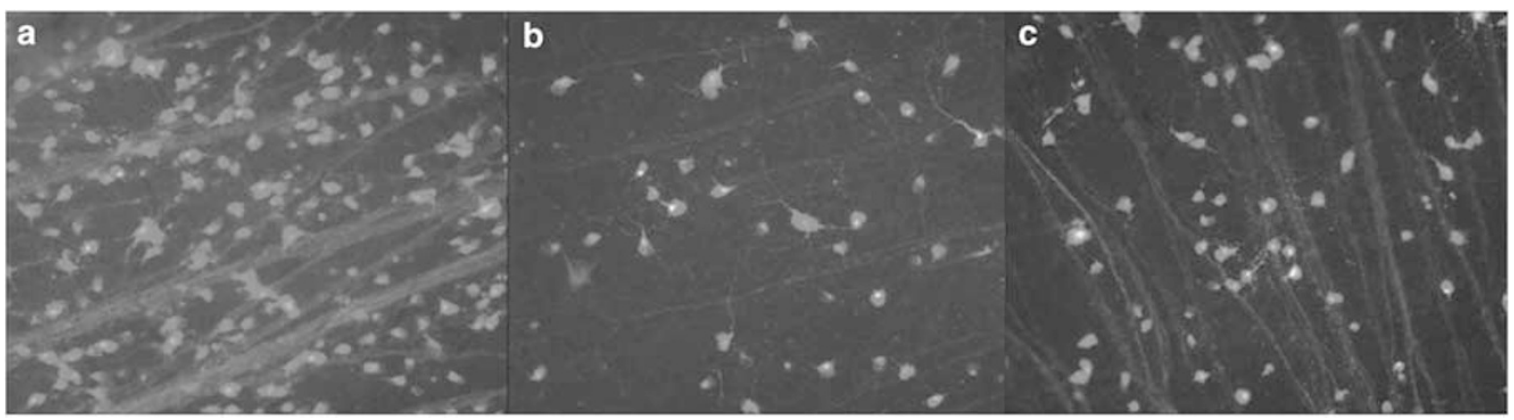

Figure 1 Fluorescence micrographs of retinal ganglion cells in normal control (a) and at 7 days after optic nerve crush injury in groups B (b) and C (c) $(\times 200)$. In the retinal areas at $1 \mathrm{~mm}$ from the optic nerve head, a significant increase in surviving retinal ganglion cells (RGCs) from group C eyes (transpupillary thermotherapy, TTT, was performed $24 \mathrm{~h}$ before the optic nerve crush injury) than group B was observed.

staining was performed at $24 \mathrm{~h}$ after TTT, at $24 \mathrm{~h}$ and 7 days after optic nerve crush injury. IHC staining was also performed at $24 \mathrm{~h}$ and 7 days after optic nerve crush injury in groups B and A (normal control). Two eyes were used for each staining. At each staining, eyes were enucleated and immersed in $4 \%$ paraformaldehyde for $2 \mathrm{~h}$. After fixation, the eyes were cut equatorially behind the ora serrata and immersed overnight in the same fixative. The eyes were embedded in paraffin and sectioned at $4 \mu \mathrm{m}$ thickness along the vertical meridian through the optic nerve head and retina. Paraffin sections were prepared, including the optic nerve head or retina, and placed on the slides. After deparaffinization and hydration, the endogenous peroxidase was inactivated by incubation with $0.3 \%$ hydrogen peroxidase in PBS. After washing with PBS, the slides were incubated with blocking solution for $5 \mathrm{~min}$. This was followed by incubation with mouse monoclonal antibodies to Hsp72 (SPA-810, StressGen Biotechnologies Corp.,

Victoria, British Columbia, Canada) $1: 150$ for $3 \mathrm{~h}$. Antigen-antibody complexes were detected by an avidin-biotin-peroxidase technique (LSAB kit; DakoCytomation). As a substrate to the peroxidase, diaminobenzidine was used to produce a brown colour in the target tissue, and the nuclei were counterstained with Mayer's hematoxylin. The stained tissues were examined with a light microscope. For a negative control of the IHC staining, the sections were incubated with blocking solution by replacing primary antibody.

To study colocalization of Hsp, we performed a double labelling procedure. For double labelling procedure, sections were incubated for $3 \mathrm{~h}$ at room temperature with mouse monoclonal antibodies to Hsp72 (SPA-810, StressGen Biotechnologies Corp.) 1:150 and rabbit polyclonal antibodies to glial fibrillary acidic protein (GFAP; DakoCytomation Inc., CA, USA) 1:500. After they were washed with PBS, the slides were incubated for $1 \mathrm{~h}$ in the dark with Alexa Fluor 488 anti-mouse IgG
( 1 : 1000, Invitrogen Molecular probes, Eugene, OR, USA) and Alexa Fluor 555 anti-rabbit IgG (1:5000, Invitrogen Molecular probes). Stained sections were examined by fluorescence microscope (BX-61, Olympus, Tokyo, Japan).

\section{Statistics}

The data were analysed with the independent samples $t$-test using the SPSS 12.0 statistical package (SPSS Inc., Chicago, IL, USA).

\section{Results}

\section{Density of surviving RGCs after optic nerve crush injury}

For the 10 eyes in group A, the mean density of RGCs in the 12 standard retinal areas was $1074.8 \pm 250.0$ per $\mathrm{mm}^{2}$ (mean $\pm \mathrm{SD}$ ). According to the distance from the optic nerve head, the mean RGC density was $1135.2 \pm 248.7$, $1068.1 \pm 247.4$, and $1021.1 \pm 258.9$ per $\mathrm{mm}^{2}$ in retinal areas 1,2 , and $3 \mathrm{~mm}$ from the optic nerve head, respectively. Mean RGC density was negatively correlated with distance from the optic nerve head (Kendall's tan-b correlation coefficient $=-0.186, P=0.042$ ). In group $B$, the mean density of RGCs in the 12 standard retinal areas significantly decreased to $252.9 \pm 96.7$ per $\mathrm{mm}^{2}$ at 7 days $(n=8)$ and to $168.7 \pm 41.8$ per $\mathrm{mm}^{2}$ at 14 days $(n=9)$ after optic nerve crush injury, respectively, $(P<0.001$, independent samples $t$-test; Figure 2). These accounted for 23.5 and $15.7 \%$ of the mean normal RGC density (group A).

\section{Effect of TTT on the survival of RGCs}

At 7 days after optic nerve crush injury, the mean density of surviving RGCs in the 12 standard areas was higher in group C $\left(372.7 \pm 149.8\right.$ per $\left.\mathrm{mm}^{2}\right)$ than in group B $\left(252.9 \pm 96.7\right.$ per $\left.\mathrm{mm}^{2}\right)$ with borderline significance $(P=0.058$, independent samples $t$-test; Table 1 ; Figure 2$)$. 

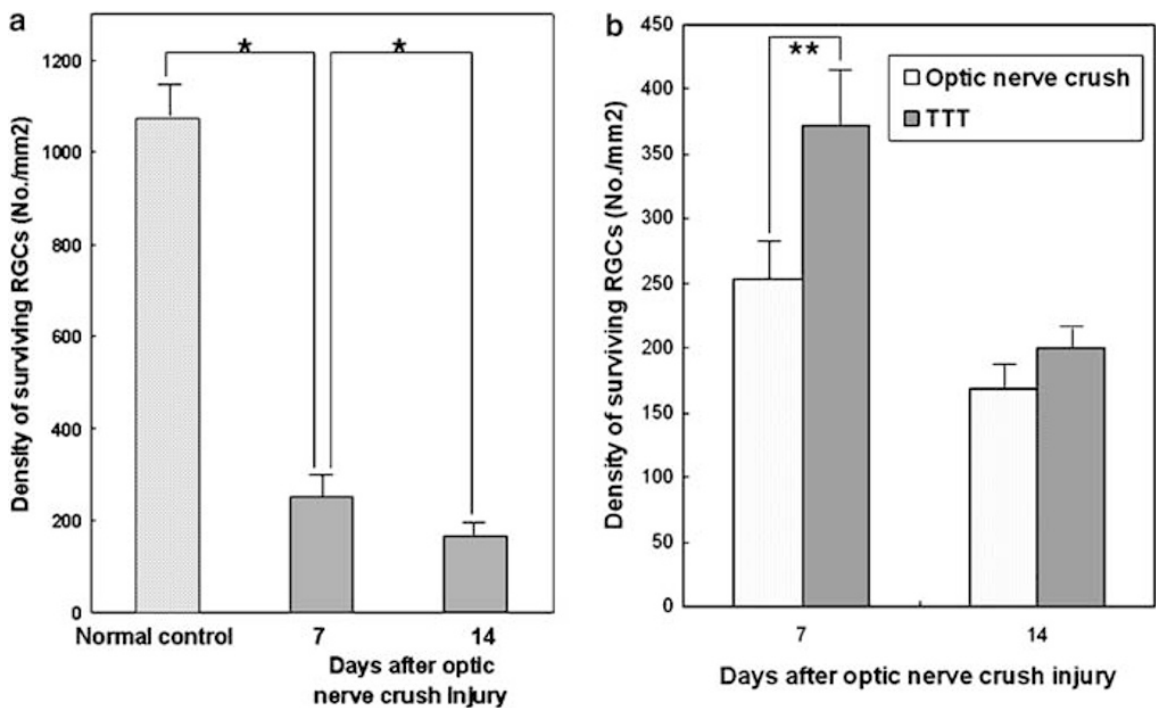

Figure 2 Mean density of surviving retinal ganglion cells (RGCs) in the whole retina. Mean density of surviving RGCs of group B (eyes which underwent optic nerve crush injury) decreased significantly at 7 and 14 days after optic nerve crush injury compared to group A (normal control) (a). In group C (eyes with transpupillary thermotherapy, TTT, $24 \mathrm{~h}$ before optic nerve crush injury), RGC density was higher with borderline significance $(P=0.058$, independent samples $t$-test) compared to eyes without prior TTT (group B) at 7 days after optic nerve crush injury, but at 14 days, RGC density was not significantly different $(P=0.085$, independent samples $t$-test) (b). ${ }^{*} P<0.05$ by independent samples $t$-test, ${ }^{* *} P=0.058$.

Table 1 Density of surviving RGCs (number per $\mathrm{mm}^{2}$; mean \pm SD) in each group at 7 and 14 days

\begin{tabular}{|c|c|c|c|c|c|}
\hline \multirow{2}{*}{ Number of eyes } & \multirow[b]{2}{*}{$\begin{array}{c}\text { Group A } \\
\text { (normal control) } \\
10\end{array}$} & \multicolumn{2}{|c|}{ Day 7} & \multicolumn{2}{|c|}{ Day 14} \\
\hline & & $\begin{array}{c}\text { Group B } \\
\text { (ON crush) } \\
8\end{array}$ & $\begin{array}{c}\text { Group C } \\
(\text { TTT) } \\
10\end{array}$ & $\begin{array}{c}\text { Group B } \\
\text { (ON crush) } \\
9\end{array}$ & $\begin{array}{c}\text { Group C } \\
\text { (TTT) } \\
10\end{array}$ \\
\hline \multicolumn{6}{|c|}{ Distance from the optic nerve head } \\
\hline $1 \mathrm{~mm}$ & $1135.2 \pm 248.7$ & $273.3 \pm 105.4$ & $422.7 \pm 165.6$ & $195.9 \pm 52.9$ & $242.6 \pm 37.0$ \\
\hline & & \multicolumn{2}{|c|}{$P=0.034^{*}$} & \multicolumn{2}{|c|}{$P=0.044$} \\
\hline $2 \mathrm{~mm}$ & $1068.1 \pm 247.3$ & \multicolumn{2}{|c|}{$P=0.069$} & $168.7 \pm 48.1$ & $193.3 \pm 38.7$ \\
\hline $3 \mathrm{~mm}$ & $1021.1 \pm 258.9$ & $224.9 \pm 85.5$ & $319.9 \pm 138.3$ & $141.5 \pm 33.0$ & $165.8 \pm 50.0$ \\
\hline Total & $1074.8 \pm 250.0$ & $252.9 \pm 96.7$ & $372.7 \pm 149.8$ & $168.7 \pm 41.8$ & $200.6 \pm 32.6$ \\
\hline
\end{tabular}

ON, optic nerve; TTT, transpupillary thermotherapy.

${ }^{*} P$-value by independent samples $t$-test between groups B and C.

In the retinal areas at $1 \mathrm{~mm}$ from the optic nerve head, a significant increase in surviving RGCs from group $C$ eyes was observed at both 7 and 14 days after optic nerve crush injury.

Bold values indicate statistically significant difference.

At 14 days, the difference was not significant (200.6 \pm 32.6 and $168.7 \pm 41.8$ per $\mathrm{mm}^{2}$ in groups $C$ and $B$, respectively; $P=0.085$, independent samples $t$-test; Table 1; Figure 2).

On the basis of distance of the RGCs from the optic nerve head, the RGC count showed a different pattern. In the retinal areas at $1 \mathrm{~mm}$ from the optic nerve head, a significant increase in surviving RGCs from group $C$ eyes was observed at both 7 and 14 days after optic nerve crush injury $(P=0.034$ and 0.044 at 7 and 14 days, respectively, independent samples $t$-test; Table 1; Figure 3). However, in retinal areas 2 and $3 \mathrm{~mm}$ from the optic nerve head, the difference of RGC density was not statistically significant $(P>0.05$, independent samples t-test; Table 1; Figure 3).

\section{Immunohistochemical staining of Hsp72 in the optic nerve head and retina}

The normal control eyes and eyes of group B showed negative staining for Hsp72 in the optic nerve head (Figure $4 \mathrm{a}-\mathrm{c}$ ). Positive staining for Hsp72 was shown in the optic nerve tissue of group $\mathrm{C}$ eyes, mainly at the 

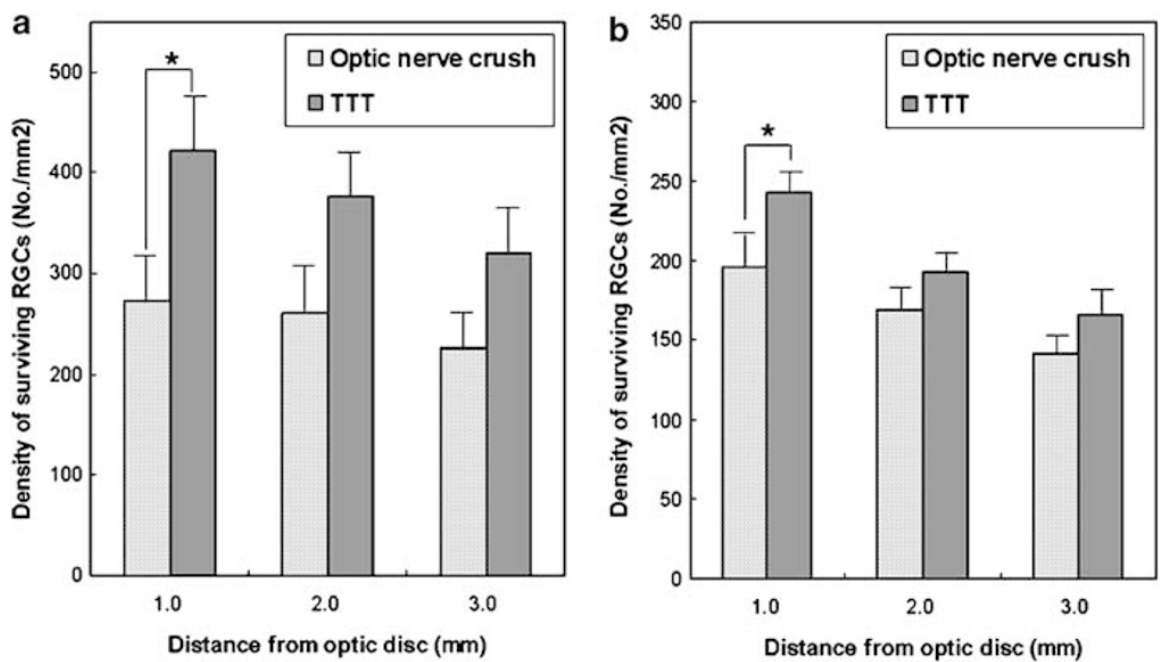

Figure 3 Mean density of surviving retinal ganglion cells (RGCs) of group B (eyes which underwent optic nerve crush injury) and group C (eyes which underwent transpupillary thermotherapy, TTT, $24 \mathrm{~h}$ before optic nerve crush injury) according to distance from the optic nerve head at 7 days (a) and 14 days (b) after optic nerve crush injury, respectively. There was a significant increase in density of surviving RGCs at $1.0 \mathrm{~mm}(P=0.034$ at 7 days and 0.044 at 14 days, independent samples $t$-test), but not at 2.0 and $3.0 \mathrm{~mm}$ from the optic nerve head at both 7 and 14 days. ${ }^{*} P<0.05$.

central portion, at $24 \mathrm{~h}$ after TTT (arrows, Figure $4 \mathrm{~d}$ ) and $24 \mathrm{~h}$ after optic nerve crush injury (arrows, Figure 4e) at the optic nerve head. At 7 days after optic nerve crush injury, faint staining for Hsp72 was shown (arrow, Figure 4f). Hsp72 immunostaining was observed in the photoreceptor inner segment layer, the outer nuclear layer, and outer part of outer plexiform layer (Figure $4 \mathrm{~g}$ and $\mathrm{h}$ ), which expression pattern is similar to previous report on Hsp72 expression in normal rat eyes. ${ }^{18}$ Retinal Hsp72 immunostaining pattern was not different between eyes of group B at $24 \mathrm{~h}$ after optic nerve crush injury (Figure $4 \mathrm{~g}$ ) and eyes of group $\mathrm{C}$ at $24 \mathrm{~h}$ after TTT (Figure 4h). In RGC layers, no reactivity was observed (Figure $4 \mathrm{~g}$ and $\mathrm{h}$ ). In double labelling staining, astrocytes were positive for Hsp72 (Figure 4i).

\section{Discussion}

This study was designed to investigate the neuroprotective effect of Hsp72 induced at the optic nerve head tissue by TTT. In the retinal areas close to the optic nerve head, a significant increase in surviving RGCs was observed in TTT group at both 7 and 14 days after optic nerve crush injury. Hsp72 has been reported to have a neuroprotective effect in glaucoma animal models. Park $e t \mathrm{al}^{6}$ reported that the induction of Hsp72 with hyperthermia or intraperitoneal zinc administration protected RGCs in a chronic IOP elevation rat model. Also, Ishii $e t$ al $^{7}$ reported RGC protection with intraperitoneal administration of geranylgeranylacetone, a heat shock protein inducer, in a chronic IOP elevation rat model. This study showed local increase of Hsp72 at the optic nerve head had a neuroprotective effect as well. Hsp70 has been shown to have a molecular chaperoning effect, and to inhibit apoptosis in some studies, which may explain the neuroprotection mechanism observed in these experiments. ${ }^{19-21}$

Unlike other methods used to induce Hsp72 such as systemic agents or hyperthermia, TTT induced Hsp72 locally only at the treated site. In this study, TTT was targeted to the optic nerve head. The optic nerve head is known as a primary site of glaucomatous optic nerve damage through which all axons of the RGCs pass. We intended to protect the tissue where the initial damage occurred; that is why we performed TTT on the optic nerve head instead of performing it on the entire retina.

Although TTT was neither targeted onto the somata of RGCs, nor was Hsp72 immunostaining observed in somata of RGCs, TTT targeted onto the optic nerve head demonstrated Hsp72 expression in the optic nerve tissue with a neuroprotective effect on the RGCs. Our finding implies that Hsp72 do not have to be primarily expressed in the somata of RGCs to provide a neuroprotective effect. The mechanism by which TTT provide neuroprotection is not clear. One possible explanation is astrocytes-to-RGCs transport of Hsp72 with subsequent axonal transport to the somata of RGCs after TTT. Hsp72 induced in the optic nerve tissue by TTT were colocalized with GFAP, a marker characteristic of astrocytes. And also, exogenous Hsp70 administered to the proximal end of the axon after axotomy has been observed to inhibit apoptosis in sensory neurons. ${ }^{22}$ Therefore, it is possible that Hsp72 was transported from astrocytes to RGCs and increased cell survival. On the other hand, the possibility 


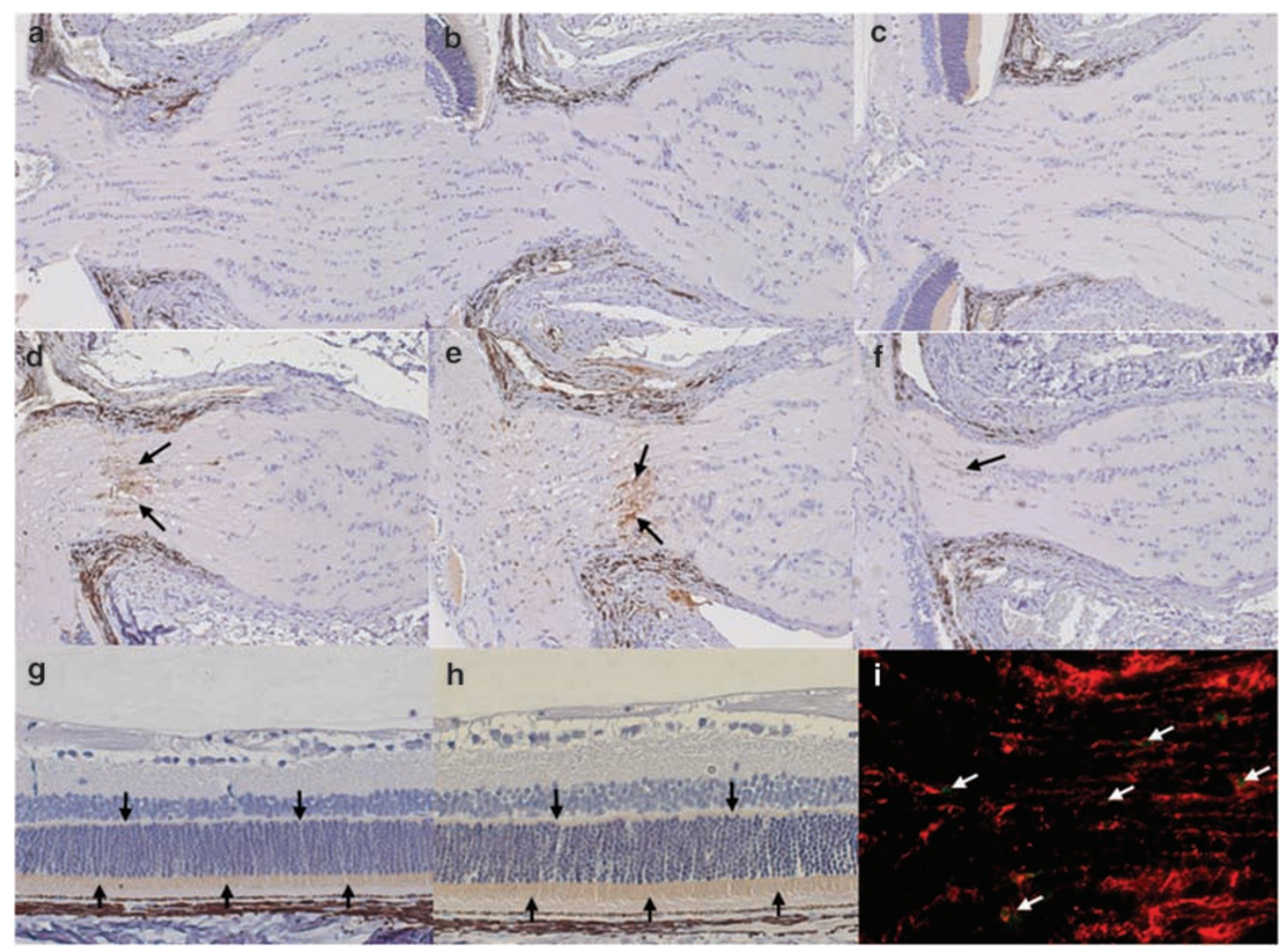

Figure 4 Immunohistochemical staining of heat shock protein (Hsp) 72 in the optic nerve head and retina. Contrary to normal control eye (a) and eyes of group B at $24 \mathrm{~h} \mathrm{(b)} \mathrm{and} 7$ days (c) after optic nerve crush injury, positive staining for Hsp72 was shown in the optic nerve tissue of group C eyes at $24 \mathrm{~h}$ after transpupillary thermotherapy, TTT (d) and $24 \mathrm{~h}$ after optic nerve crush injury (e) (arrows). At 7 days after optic nerve crush injury, weak staining for Hsp72 was shown (arrow, f). Hsp72 immunostaining was observed in the photoreceptor inner segment layer, the outer nuclear layer, and outer part of outer plexiform layer (arrows, g and h). Retinal Hsp72 immunostaining pattern was not different between eyes of group B at $24 \mathrm{~h}$ after optic nerve crush injury (g) and eyes of group C at $24 \mathrm{~h}$ after TTT (h). In double immunofluorescence labelling staining, astrocytes were also positive for Hsp72 (green, Hsp72; orange, glial fibrillary acidic protein, GFAP; arrows, i).

that Hsp72 expression in optic nerve head astrocytes provides neuroprotection regardless of the presence of Hsp72 inside of the RGCs cannot be excluded.

In the present study, the use of TTT induced reduction of RGC loss in retinal areas close to the optic nerve head. This may be in part due to the site of Hsp72 expression and characteristic nerve fibre distribution. Peripheral fibres run closer to the choroid and exit in the periphery of the optic nerve. Whereas fibres originating closer to the optic nerve head are situated closer to the vitreous and occupy a more central portion of the optic nerve head. Also, IHC staining for Hsp72 showed a positive staining mainly at the central portion of optic nerve head (Figure 4). Therefore, if TTT increases the expression of Hsp72 more in the central portion of optic nerve head, RGCs closer to the optic nerve head will be rescued more from the crush injury. In addition, different susceptibility among the different subtypes of RGCs may contribute to these findings. It has been reported that rat RGCs can be classified into several types according to their morphology. ${ }^{23}$ Moreover, Hou B et al ${ }^{24}$ reported that inosine exhibited a better protective effect for RGCs closer to the optic nerve head. This implies the possibility of topographic differences in neuronal vulnerability.

In conclusion, use of TTT increased the survival of RGCs in retinal areas close to the optic nerve head in the optic nerve crush injury model of the rat. This approach might provide a novel therapy for glaucoma using induction of Hsp72 in the optic nerve head especially to save the central vision rather than peripheral. As Hsp70 is also induced in the retina by IOP elevation only, contrary to optic nerve crush injury in this study, whether TTT can induce more Hsp70 with resulting neuroprotection should be further investigated.

\section{Acknowledgements}

None. 


\section{References}

1 Chopp M, Chen H, Ho KL, Dereski MO, Brown E, Hetzel FW et al. Transient hyperthermia protects against subsequent forebrain ischemic cell damage in the rat. Neurology 1989; 39: 1396-1398.

2 Caprioli J, Kitano S, Morgan JE. Hyperthermia and hypoxia increase tolerance of retinal ganglion cells to anoxia and excitotoxicity. Invest Ophthalmol Vis Sci 1996; 37: 2376-2381.

3 Tsuchiya D, Hong S, Matsumori Y, Kayama T, Swanson RA, Dillman WH et al. Overexpression of rat heat shock protein 70 reduces neuronal injury after transient focal ischemia, transient global ischemia, or kainic acid-induced seizures. Neurosurgery 2003; 53: 1179-1187.

4 Kalmar B, Burnstock G, Vrbova G, Urbanics R, Csermely P, Greensmith L. Upregulation of heat shock proteins rescues motoneurones from axotomy-induced cell death in neonatal rats. Exp Neurol 2002; 176: 87-97.

5 Tidwell JL, Houenou LJ, Tytell M. Administration of Hsp70 in vivo inhibits motor and sensory neuron degeneration. Cell Stress Chaperones 2004; 9: 88-98.

6 Park KH, Cozier F, Ong OC, Caprioli J. Induction of heat shock protein 72 protects retinal ganglion cells in a rat glaucoma model. Invest Ophthalmol Vis Sci 2001; 42: 1522-1530.

7 Ishii Y, Kwong JM, Caprioli J. Retinal ganglion cell protection with geranylgeranylacetone, a heat shock protein inducer, in a rat glaucoma model. Invest Ophthalmol Vis Sci 2003; 44: 1982-1992.

8 Mainster MA, Reichel E. Transpupillary thermotherapy for age related macular degeneration: long-pulse photocoagulation, apoptosis, and heat shock proteins. Ophthalmic Surg Lasers 2000; 31: 359-373.

9 Journee-de Korver JG, Keunen JE. Thermotherapy in the management of choroidal melanoma. Prog Retin Eye Res 2002; 21: 303-317.

10 Mochizuki Y, Noda Y, Enaida H, Hata Y, Ueno A, Yoshikawa $\mathrm{H}$ et al. Retinal capillary hemangioma managed by transpupillary thermotherapy. Retina 2004; 24: 981-984.

11 Abramson DH, Schefler AC. Transpupillary thermotherapy as initial treatment for small intraocular retinoblastoma: technique and predictors of success. Ophthalmology 2004; 111: 984-991.

12 Ming Y, Algvere PV, Odergren A, Berglin L, van der Ploeg I, Seregard $\mathrm{S}$ et al. Subthreshold transpupillary thermotherapy reduces experimental choroidal neovascularization in the mouse without collateral damage to the neural retina. Invest Ophthalmol Vis Sci 2004; 45: 1969-1974.

13 Thach AB, Sipperley JO, Dugel PU, Sneed SR, Park DW, Cornelius J. Large-spot size transpupillary thermotherapy for the treatment of occult choroidal neovascularization associated with age-related macular degeneration. Arch Ophthalmol 2003; 121: 817-820.

14 Kim JM, Park KH, Kim YJ, Park HJ, Kim DM. Thermal injury induces heat shock protein in the optic nerve head in vivo. Invest Ophthalmol Vis Sci 2006; 47: 4888-4894.

15 Sarikcioglu L, Demir N, Demirtop A. A standardized method to create optic nerve crush: Yasargil aneurysm clip. Exp Eye Res 2007; 84: 373-377.

16 Kaneko T, Saeki K, Lee T, Mizuno N. Improved retrograde axonal transport and subsequent visualization of tetramethylrhodamine (TMR)-dextran amine by means of an acidic injection vehicle and antibodies against TMR. J Neurosci Methods 1996; 65: 157-165.

17 Fritzsch B. Fast axonal diffusion of 3000 molecular weight dextran amines. J Neurosci Methods 1993; 50: 95-103.

18 Dean DO, Kent CR, Tytell M. Constitutive and inducible heat shock protein 70 immunoreactivity in the normal rat eye. Invest Ophthalmol Vis Sci 1999; 40: 2952-2962.

19 Hartl FU. Molecular chaperones in cellular protein folding. Nature 1996; 381: 571-579.

20 Mailhos C, Howard MK, Latchman DS. Heat shock protects neuronal cells from programmed cell death by apoptosis. Neuroscience 1993; 55: 621-627.

21 Li CY, Lee JS, Ko YG, Kim JI, Seo JS. Heat shock protein 70 inhibits apoptosis downstream of cytochrome c release and upstream of caspase-3 activation. J Biol Chem 2000; 275: 25665-25671.

22 Houenou LJ, Li L, Lei M, Kent CR, Tytell M. Exogenous heat shock cognate protein Hsc70 prevents axotomy-induced death of spinal sensory neurons. Cell Stress Chaperones 1996; 1: $161-166$.

23 Sun W, Li N, He S. Large-scale morophological survey of rat retinal ganglion cells. Vis Neurosci 2002; 19: 483-493.

24 Hou B, You SW, Wu MM, Kuang F, Liu HL, Jiao XY et al. Neuroprotective effect of inosine on axotomized retinal ganglion cells in adult rats. Invest Ophthalmol Vis Sci 2004; 45: 662-667.

25 Sakai M, Sakai H, Nakamura Y, Fukuchi T, Sawaguchi S. Immunolocalization of heat shock proteins in the retina of normal monkey eyes and monkey eyes with laser-induced glaucoma. Jpn J Ophthalmol 2003; 47: 42-52. 